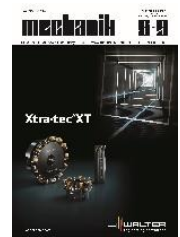

How to cite this article:

Authors: Piotr Danielczyk, Jacek Stadnicki

Title of article: „Estimation of exploitation safety of welded grate of eccentric press””

Mechanik, No. 8-9 (2019)

DOI: https://doi.org/10.17814/mechanik.2019.8-9.66

\title{
Estimation of exploitation safety of welded grate of eccentric press
}

\section{PIOTR DANIELCZYK \\ JACEK STADNICKI*}

Dr inż. Piotr Danielczyk (pdanielczyk@ath.bielsko.pl), https://orcid.org/0000-0002-7622-3150 - Akademia Techniczno-Humanistyczna, Bielsko-Biała, Polska

Prof. dr hab. inż. Jacek Stadnicki (jstadnicki@ath.bielsko.pl), https://orcid.org/0000-0002-3297-3291 - Akademia Techniczno-Humanistyczna, Bielsko-Biała, Polska

The fatigue strength of welds of the press body for pressing car body sheets were analyzed. The FEM models of the body were prepared taking into account welded sheet metal connections. Simulation, which took into account the damage of some welds, showed insufficient stiffness of the press grate, which in consequence caused a fatigue fracture of the eccentric press shaft.

KEYWORDS: fatigue strength, press grate, FEM simulation

\section{Introduction}

Welded structures made of steel sheets are used in the bodies and housings of modern machines. Compared to previously used gray iron cast structures, they are cheaper and lighter, however their ability to damp vibrations and fatigue strength at high cycle loads are lower.

The subject of the high-cycle fatigue strength analysis was the crown of an eccentric press for stamping the car body sheets, which failed. The crown of the press in the form of a grate with a box-like welded structure with mounted housings of four slide bearings supporting the eccentric shaft of the press is made of steel sheets with a thickness of 10 to $50 \mathrm{~mm}$.

Fig. 1 shows the press, and fig. 2 illustrates bottom view of the grate of the press crown, which indicates: the mounting places of the eccentric shaft bearing housings, places where the press crown is supported on the pillars, and schematically - the press shaft.

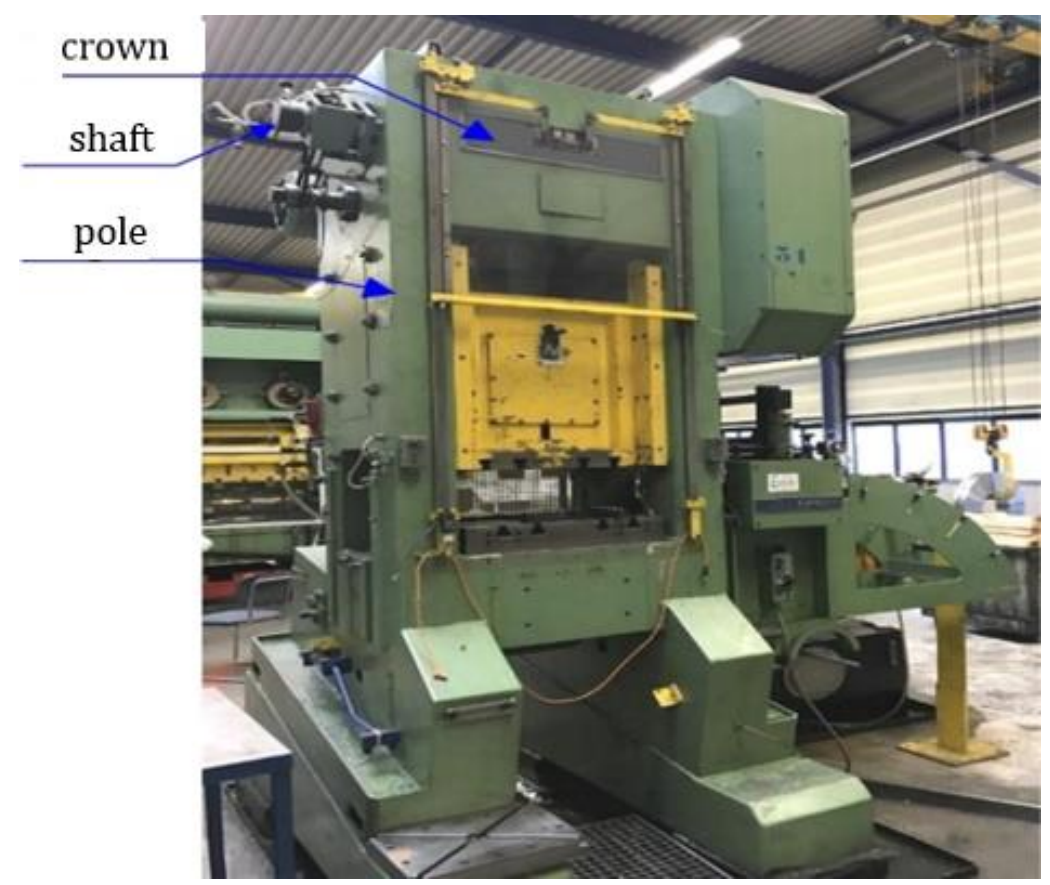

Fig. 1. The analyzed press 


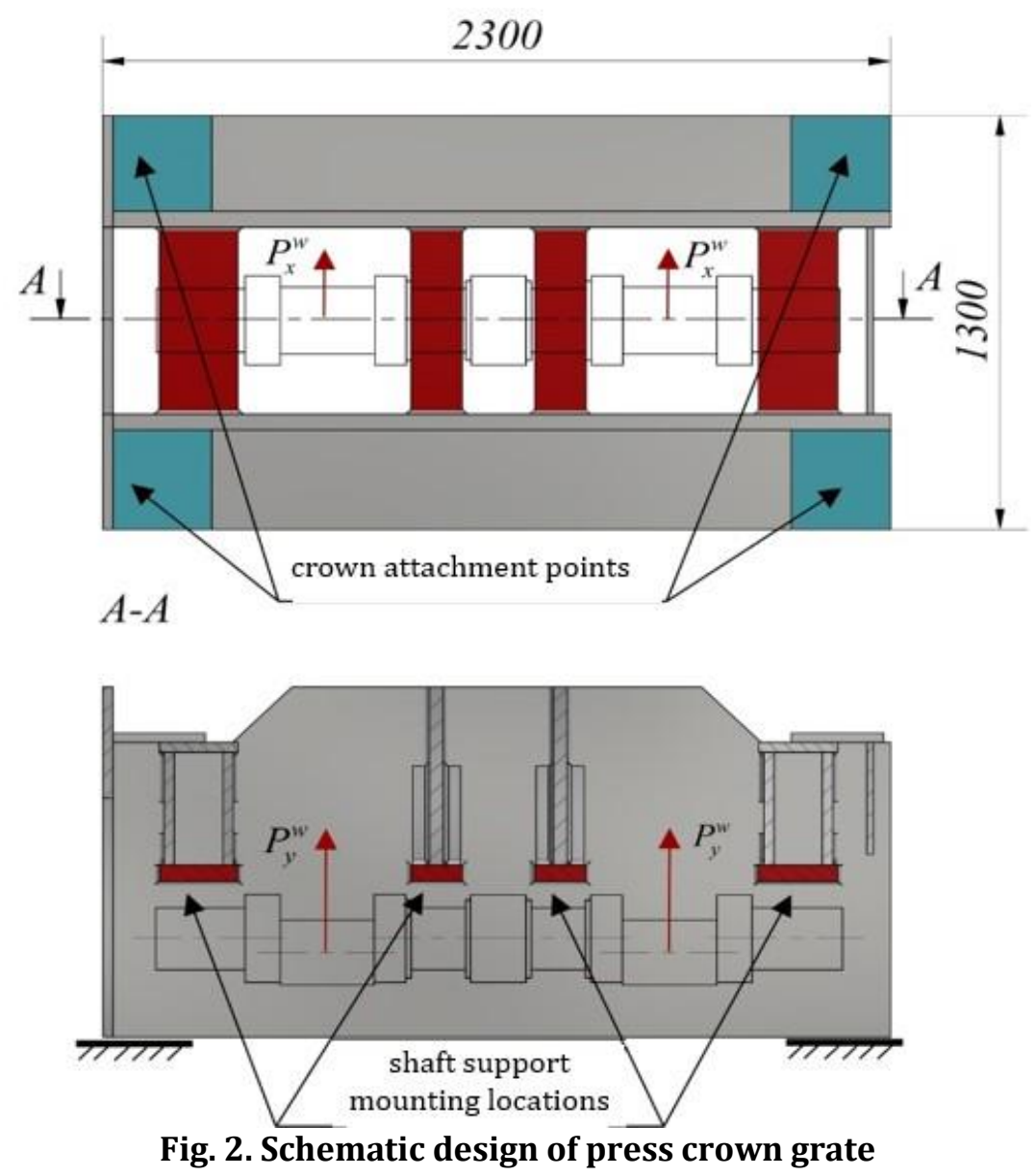

During the operation of the press carried out in accordance with technical conditions specified by the manufacturer, a failure occurred due to the fatigue fracture of the eccentric shaft. During determination of the failure causes, the press crown grate was also inspected and it was found that part of the grate welds on one side was cracked. The question arose: what was the primary cause of the failure? Did the shaft break cause part of the grate joints to crack, or conversely, weakened by cracks, the grate caused a fatigue fracture of the shaft? To explain this, the fatigue strength of the shaft and grate of the press crown was analyzed using FEM models and the ANSYS Workbench program.

\section{FEM model and evaluation of fatigue strength of the press crown grate}

Computational model of the press crown was developed using the finite element method and the ANSYS Workbench program. The geometric model imported from the CAD environment was discredited using 3D finite elements type Solid186 and Solid187, with regular distribution of finite element mesh nodes (fig. 3). It was assumed that the support of the press crown is rigid, and the loads acting at the places of mounting the shaft supports come from the reactions determined during a separate analysis carried out for the shaft. The analysis of the eccentric shaft of the press is described in paper [1].

The FEM model of the crown consisted of 1336553 finite elements connected in 290427 nodes. The calculation model took into account that part of the welds of the press crown grate was cracked.

Fillet welds in the finite element method can be modeled using a surface and solid model. 


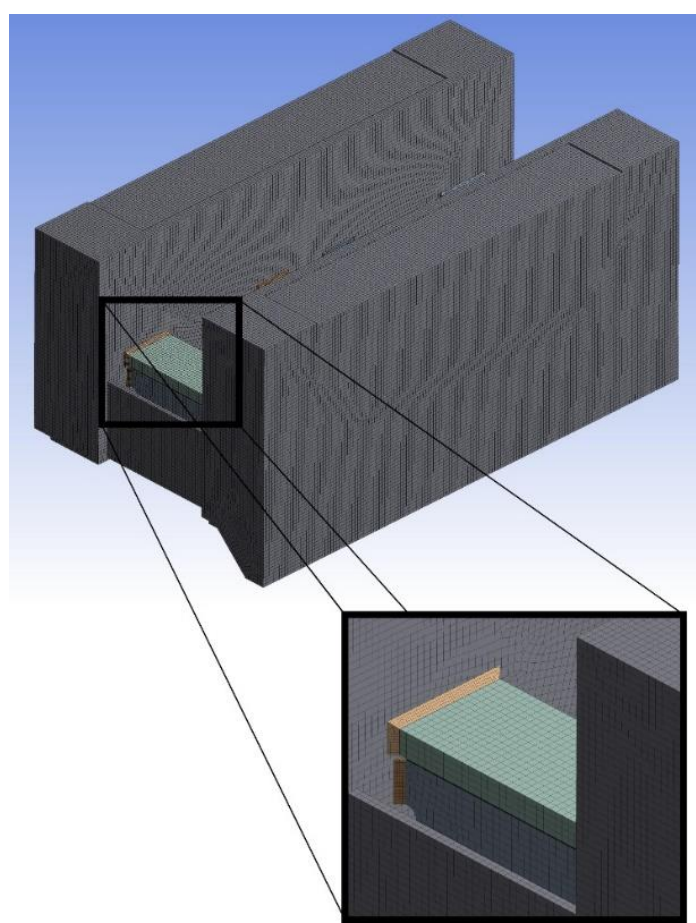

Fig. 3. FEM model of the press crown

\section{Surface model}

This modeling method requires creating the surface models of welded sheets and surface models of welds joining sheets. The idea of this method of modeling the joint is shown in fig. 4 . The fillet weld is replaced by a shell surface element of equivalent thickness $t$. Two approaches are used.

In the first approach, the modeled weld consists of two rows of shell finite elements, which are assigned a thickness corresponding to the dimension of the weld $a$. The arrangement of the surface elements modeling welded sheets should be such that the surface of the weld model is parallel to the face of the actual weld [2]. This approach works well when modeling joints of metal sheets of similar thickness.

The second approach $[2,4]$ consists in replacing parts of welded sheets within the joint with surface elements of equivalent thickness $g$, being the sum of sheet thickness $t$ and weld dimension $a$.

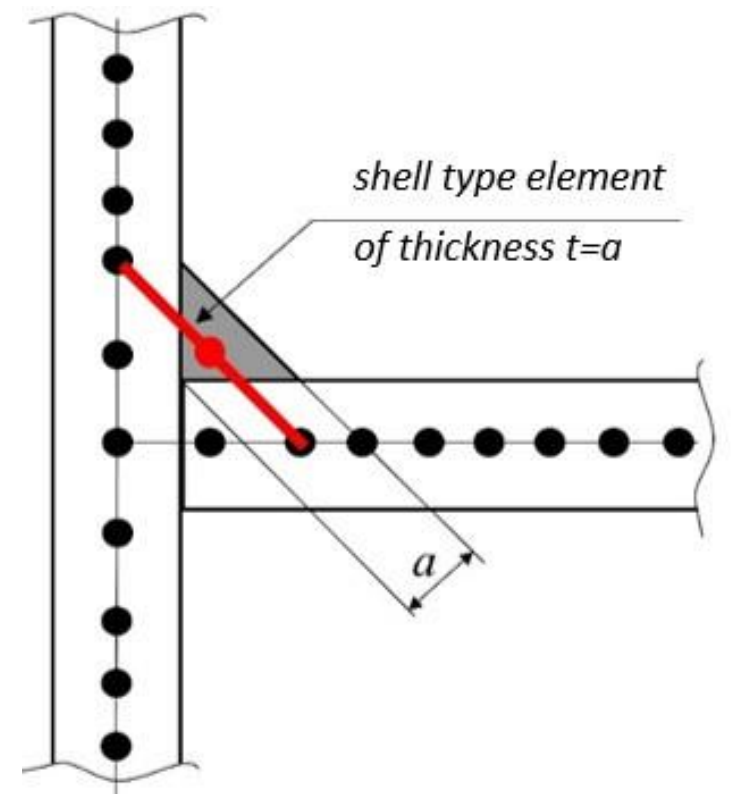

Fig. 4. Modeling of the weld with a substitute element 
Arrangements of nodes, on which surface elements modeling a weld are spliced are shown in fig. 5. Similarly, welds are also replaced with rigid elements, as described in paper [3]. It is worth noting that surface models are numerically more effective than the solid models described below.

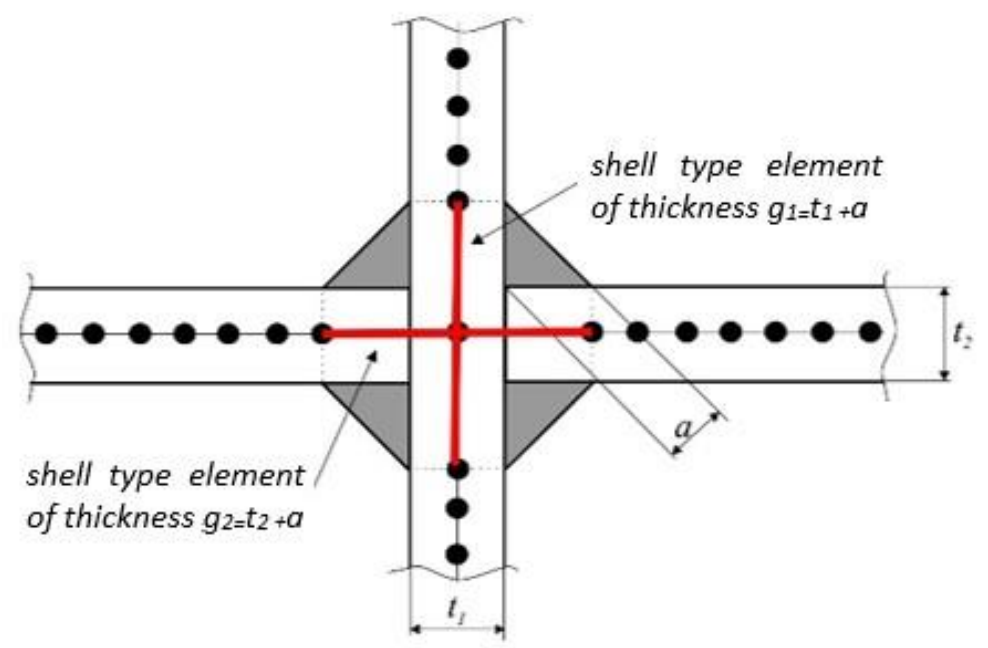

Fig. 5. Modeling of the weld with an element of equivalent thickness

\section{Solid model}

This modeling method is widely used because of the ease of creating a FEM connection model, which is based on a 3D geometric model imported into the FEM program from CAD. In calculations carried out using such models, one can accurately reproduce the cross-section and shape of the weld face, penetration depth, as well as the thickness of the welded sheets, which can vary significantly. After calculations, an accurate stress distribution is obtained in the weld and sheets to be joined. Specialized programs for simulating welding also allow to determine the phase and temperature distribution in the melted material and welding deformations.

Solid models are numerically less effective, therefore, to improve their efficiency, the modeling of welded joints uses the technique of creating auxiliary models (sub-modeling), in which fragments covering the welded joint are accurately reproduced using compacted mesh nodes.

Because the purpose of the analysis was to assess the fatigue strength of the entire press crown grate, and the sheets, from which it is welded, have very different thicknesses, a solid model was used to model the welded joints.

Connections of finite elements of the solid type modeling sheets and welds were modeled with Bonded type contact elements. They ensure equal force and nodal displacements at the connection point.

A Wöhler curve (the so-called S-N curve) was introduced into the model for S235JR steel, from which the press crown was made. The load on the press crown grate was the reactions in the eccentric shaft bearing supports, derived from the technological process, with the values: $P_{x} w=5.69 \mathrm{kN}$ and $P_{y^{w}}=998 \mathrm{kN}$, which were evenly distributed over the nodes of the FEM model in places where the shaft supports are mounted (see fig. 2 ). The load was a zero-pulsating cycle with amplitudes equal to the reaction values. A detailed description of determining the reaction in the eccentric shaft supports is provided in paper [1].

Numerical simulations were carried out for two cases: in one - all the welds of the press crown grate were undamaged, and in the other - part of the welds of the press crown grate was damaged.

\section{Case: All welds on the press crown grate are intact}

Fig. 6a presents nodal displacements, and fig. $6 \mathrm{~b}$ - distribution of the value of the safety factor due to high cycle fatigue, calculated for welds in relation to the limit fatigue strength approximated by Goodman's equation. From fig. $6 \mathrm{a}$, it can be seen that vertical components of displacements slightly exceeded $0.16 \mathrm{~mm}$. Because the radial clearance in the shaft bearings was $0.2 \mathrm{~mm}$, deformations of the press crown grate did not significantly affect the fatigue strength of the press shaft.

Distribution of the value of the safety factor due to fatigue, shown in fig. $6 \mathrm{~b}$ for welds in the middle part of the press crown grate, shows that in several places, value of the safety factor was close to one; e.g. in the place marked in fig. $6 \mathrm{~b}$, the safety factor was 1.17 . 
a)
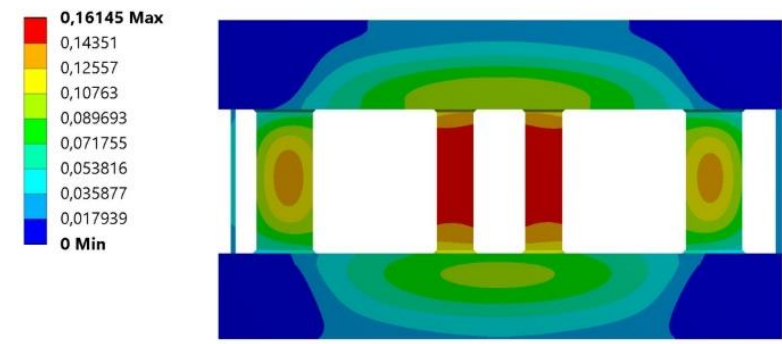

b)

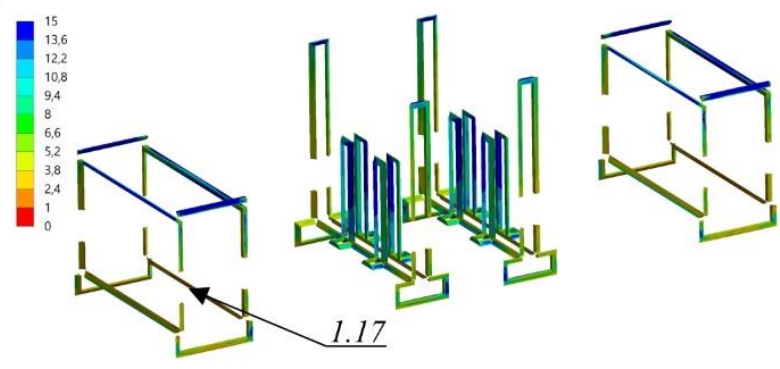

Fig. 6. Calculation results for the model without cracks in the welds: a) displacement [mm], b) contour lines of the safety factor

Considering the simplifications made during modeling, involving the assumption of the ideal shape of plates and welds, and the margin of error of the solid material model, and above all the S-N curve, it should be stated that there was a risk of exceeding the fatigue limit strength. This situation actually happened. Therefore, when assessing the safety of press operation, it can be stated that the primary reason for the machine failure was exceeding the fatigue strength of welded joints of the press crown grate.

Case: Part of the welds of the press crown grate are damaged

Inspection of the press crown grate after a failure showed that some welds were cracked (see figs. $6 \mathrm{~b}$ and $7 \mathrm{~b}$ ). In this case, changes were made to the FEM model of the grate, consisting of removing the Bonded type contact elements from the weld models at the places of cracks. Another simulation was carried out, the results of which are shown in figs. 7a and 7b. Comparison of simulation results shown in figs. 6 and 7 shows that values of vertical components of displacements on supports increase fourfold to approximately $0.64 \mathrm{~mm}$, and in a significant part of the welds, the values of the safety factor for fatigue are less than one.

a)

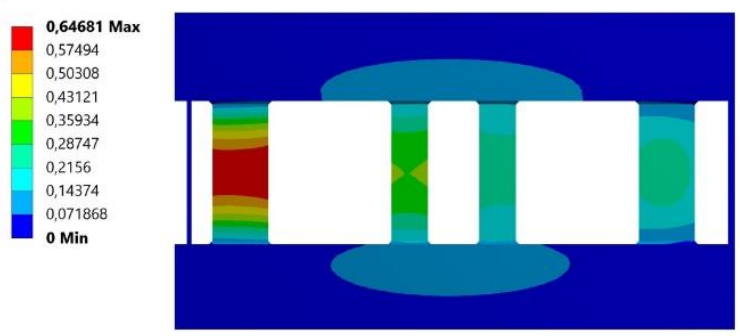

b)

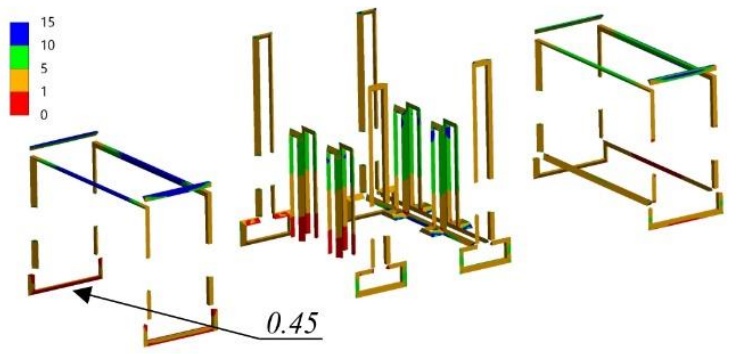

Fig. 7. Calculation results for the model, including cracks in the welds: a) displacement [mm], b) contour lines of the safety factor 


\section{Summary}

Evaluation of the eccentric press operation safety showed that the primary reason for the machine failure was exceeding the fatigue strength limit in some of the welded joints of the press crown grate. The grate weakened by cracks significantly reduced its rigidity so that it caused a fatigue fracture of the eccentric shaft of the press and machine failure.

Based on the results of the simulations of fatigue strength, changes in the design of those welded joints that were cracked were proposed. The changes consisted of welding reinforcements in the form of an additional 10 $\mathrm{mm}$ flat bar parallel to the face of fillet welds.

An analysis of the fatigue strength of the press crown grate was carried out with additional reinforcements. It shows that the improved design meets the requirements of safe machine operation.

The FEM model of the eccentric shaft of the press described in the paper showed that the reason for the failure caused by fatigue fracture was excessively high compliance of the press crown grate, to which the bearings supporting the shaft are attached.

The improved FEM model, which took into account the flexibility of bearing housings, provided results consistent with reality and enabled diagnosis of the primary cause of shaft failure, which was the fracture of part of the press crown grate.

\section{REFERENCES}

[1] Danielczyk P., Stadnicki J. „Analiza wytrzymałości zmęczeniowej wału mimośrodowego prasy”. Mechanik.7 (2019): 471-473

[2] Niemi E., Stress determination for Fatigue Analysis of Welded Components, IIW doc. IIS/IIW-1221-93, The Iternational Institute of Welding, 1995.

[3] Fayard J., Bignonnet A., Dang Van K. "Fatigue design criterion for welded structures". Fatigue \& Fracture of Engineering Materials \& Structures. 19 (1996): 723-729.

[4] Eriksson A., Lignell A.M., Olsson C., Spennare H., Weld evaluation using FEM - A guide to fatigue-loaded structures. Industrilitteratur AB, Gothenburg, Sweden, 2003. 